\title{
Within- and across-breed genomic predictions and genomic relationships for Western Pyrenees dairy sheep breeds Latxa, Manech, and Basco-Béarnaise
}

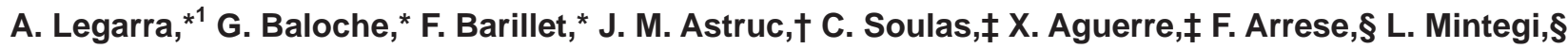 \\ M. Lasarte,\# F. Maeztu,II I. Beltrán de Heredia,ף and E. Ugarteף \\ *INRA, UR1388 GenPhySe, CS-52627, F-31326 Castanet-Tolosan, France \\ †Institut de l'Elevage, 149 rue de Bercy, F-75595 Paris, France \\ $\ddagger$ CDEO, Route de Musculdy, Quartier Ahetzia, F-64130 Ordiarp, France \\ §ARDIEKIN, Apdo 46, 01080 Vitoria-Gasteiz, Spain \\ \#ASLANA, c/Aintziburu, 31170 Iza, Spain \\ IIINTIA SA, Avda. Serapio Huici 22, 31610 Villava, Spain \\ INEIKER-Tecnalia, Apdo 46, 01080 Vitoria-Gasteiz, Spain
}

\section{ABSTRACT}

Genotypes, phenotypes and pedigrees of 6 breeds of dairy sheep (including subdivisions of Latxa, Manech, and Basco-Béarnaise) from the Spain and France Western Pyrenees were used to estimate genetic relationships across breeds (together with genotypes from the Lacaune dairy sheep) and to verify by forward cross-validation single-breed or multiple-breed genetic evaluations. The number of rams genotyped fluctuated between 100 and 1,300 but generally represented the 10 last cohorts of progeny-tested rams within each breed. Genetic relationships were assessed by principal components analysis of the genomic relationship matrices and also by the conservation of linkage disequilibrium patterns at given physical distances in the genome. Genomic and pedigree-based evaluations used daughter yield performances of all rams, although some of them were not genotyped. A pseudo-single step method was used in this case for genomic predictions. Results showed a clear structure in blond and black breeds for Manech and Latxa, reflecting historical exchanges, and isolation of Basco-Béarnaise and Lacaune. Relatedness between any 2 breeds was, however, lower than expected. Single-breed genomic predictions had accuracies comparable with other breeds of dairy sheep or small breeds of dairy cattle. They were more accurate than pedigree predictions for 5 out of 6 breeds, with absolute increases in accuracy ranging from 0.05 to 0.30 points. They were significantly better, as assessed by bootstrapping of candidates, for 2 of the breeds. Predictions using multiple populations only marginally increased the accuracy for a couple of breeds. Pooling

Received November 21, 2013.

Accepted February 2, 2014.

${ }^{1}$ Corresponding author: andres.legarra@toulouse.inra.fr populations does not increase the accuracy of genomic evaluations in dairy sheep; however, single-breed genomic predictions are more accurate, even for small breeds, and make the consideration of genomic schemes in dairy sheep interesting.

Key words: genomic selection, dairy sheep, best linear unbiased predictor (BLUP), principal component, linkage disequilibrium

\section{INTRODUCTION}

Dairy sheep husbandry in the French and Spanish Western Pyrenees benefits from genetic improvement schemes, based on performance recording and progeny testing via AI (e.g., Barillet, 1997; Ugarte, 2007). These schemes where set up in France in the 1970s and in Spain in the 1980s in the regions of Aquitaine (France) and Navarra and Basque Country (Spain). Involved breeds (as shown in the map in Figure 1) include the Basco-Béarnaise (BB) breed (France) and the Latxa (Spain) and Manech (France) populations. According to the color of the head, the Manech are subdivided into blond head [Manech Tête Rousse (MTR)] and black [Manech Tête Noire (MTN)] strains. The Latxa are equally subdivided into blond [Latxa Cara Rubia (LCR)] and black strains. However, the black strain is divided in Spain into 2 noncontiguous regions with slightly different morphology [Latxa Cara Negra Navarra (LCNNAF) and Latxa Cara Negra Euskadi (LCNEUS)] as opposed to 1 MTN strain in France. This makes for 6 populations. The Carranzana breed, also from the Spanish Basque Country, was not involved in this work because of its very small size.

Exchanges or crosses of animals across different colors are almost nonexistent. However, Latxa and Manech are perceived as the same population even across the borderline. Indeed, as a result of the Pyrenees being of low altitude and composed of mountain pastures to a 

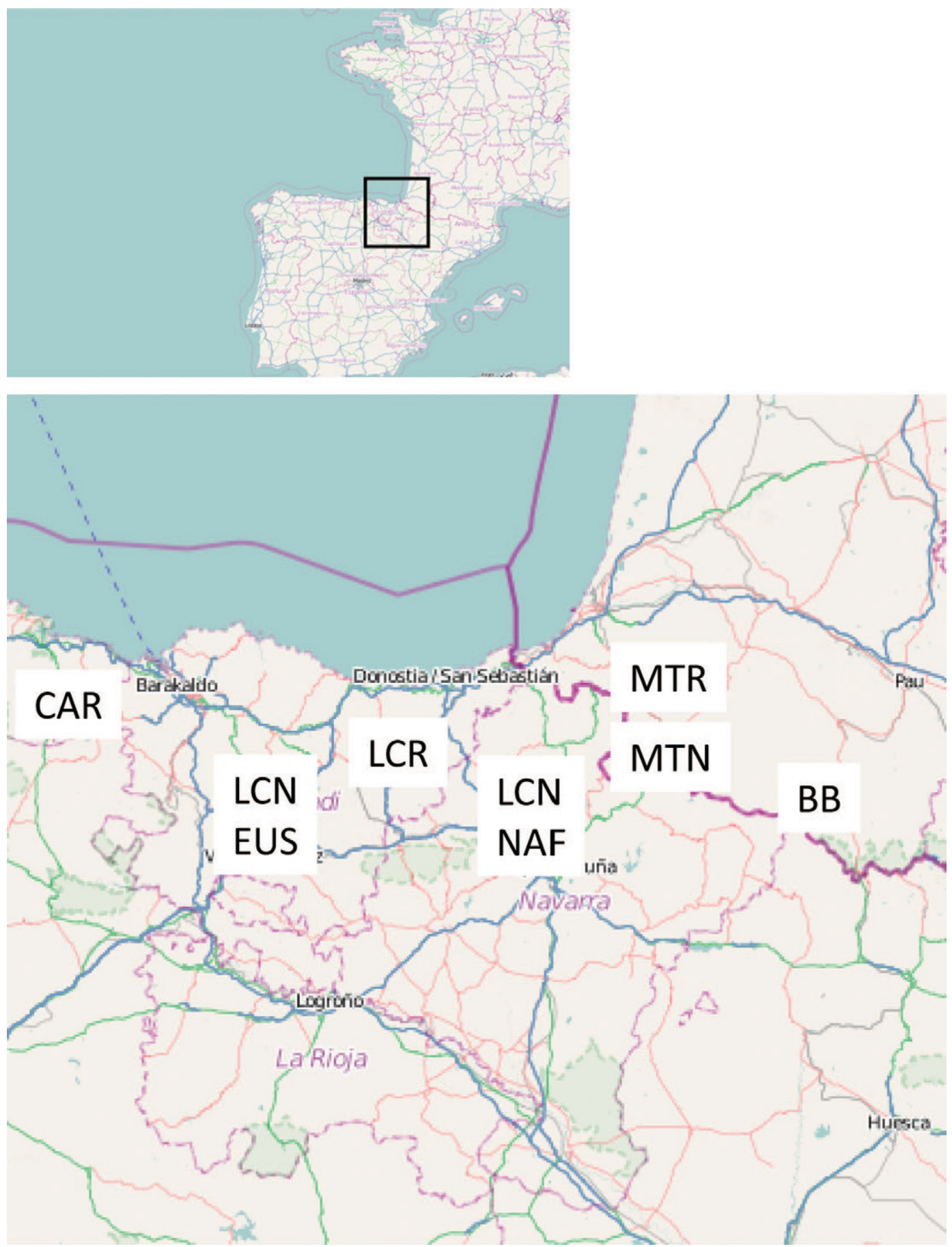

Figure 1. Localization of dairy sheep breeds in the Western Pyrenees. BB = Basco-Béarnaise; MTN = Manech Tête Noire; MTR $=$ Manech Tête Rousse; LCNEUS = Latxa Cara Negra Euskadi; LCNNAF = Latxa Cara Negra Navarre; LCR = Latxa Cara Rubia; CAR = Carranzana. Color version available in the online PDF.

great extent, exchanges of animals within a color are customary. For instance, during the 1970s, when the MTR flocks were introduced in the French Basque hills, French breeders would buy animals in Spain (F. Barillet, unpublished data); on the other hand, old transhumant shepherds would move from the mountains of Spain to French winter pastures, some mountain pastures were shared, and so on.

Furthermore, and because the French selection schemes started earlier, importation of living rams and 
semen from the French MTR has been recurrent since the 1990s in the Spanish LCR scheme. For instance, 305 MTR rams have been used on the LCR recorded population from 2001 to 2012 . This process was already analyzed by Ugarte et al. (1996), who showed higher breeding values of animals of MTR origin in the LCR scheme. Joint pedigree-based genetic evaluation of LCR and MTR has not been considered so far but is likely to be included in the future, at least in the form of including foreign information (Legarra et al., 2007; Vandenplas and Gengler, 2012) of the MTR fathers for the genetic evaluation of their sons (LCR rams). Across the 3 black strains, these AI connections are sporadic but it is accepted that, historically, these populations have been connected somehow.

Because of the use of fresh semen and high costs of milk recording and AI per animal, dairy sheep schemes need lots of organization for progeny testing, AI, and performance recording. Alleviating any of the complexities linked to these aspects would result in economic or organizational simplifications, or both. For instance, using AI rams without waiting for progeny test results would permit a quicker turnover of males, reducing the number of rams in the AI centers (which is in the hundreds and can represent a sizeable cost).

Therefore, dairy sheep schemes need a technical and economical evaluation of genomic predictions. On one hand, the population of progeny-tested rams is bigger (relative to population size) than its dairy cattle counterpart. On the other hand, fresh-semen AI needs a large population of rams and reduces the ability to progeny test rams as accurately as in dairy cattle. These are typically tested with a first crop of 20 to 40 daughters.

In addition, the cost of genotyping is relatively high for a candidate for selection. Therefore, there has been much interest in evaluating the performance of genomic prediction in dairy sheep. In the Lacaune breed, Duchemin et al. (2012) showed increases in accuracy from 0.37 (using pedigree information) to 0.42 (using genomic predictions) for milk yield. Baloche et al. (2014), following stricter Interbull guidelines and using the single-step genetic evaluation (Aguilar et al., 2010; Christensen and Lund, 2010), showed an increase in accuracy from 0.26 to 0.42 for milk yield, similar gains for other traits, and a reduction on bias. The Lacaune breed has, however, the largest reference population $(2,892 \mathrm{rams}$ in the aforementioned analysis; around 400 progeny-tested rams per year). This is not the case for the Western Pyrenees breeds above mentioned, which oscillate between 140 (MTR) and 15 (LCNNAF) progeny-tested rams per year.

It has been reported (Hayes et al., 2009; Erbe et al., 2012; Karoui et al., 2012; Olson et al., 2012) that sometimes an interest exists in pooling together several populations to create a larger reference population; this seems to be particularly true for traits partially controlled by genes of large effect (most of the examples above), or if the populations are strongly connected (Lund et al., 2011; Jorjani et al., 2012). One such gene of large effect exists in Churra dairy sheep (GarcíaGámez et al., 2012), affecting milk contents (but not yields). Its presence has not been detected so far in Latxa or any French breed, including Lacaune.

Therefore, the objectives of this work were to (1) evaluate the accuracy of genomic predictions with respect to pedigree predictions within populations, (2) evaluate the possible interest of across-population pooled genomic predictions for these close breeds, and (3) describe the relationships, as verified through marker information, across these populations.

\section{MATERIALS AND METHODS}

\section{Pseudo-Phenotypes}

All concerned breeds have performance recording based on the International Committee for Animal Recording (2012) rules. However, recording is only homogeneous for milk yield. Although French breeds record milk composition across all flocks (but only for first-parity ewes), in Spain, only part of the flocks (but all sheep in the flock) have this kind of recording. Udder morphology is scored in Spain but not in these French breeds. Therefore, total milk yield was the only trait considered (from weaning of the lamb, $30 \mathrm{~d}$ after lambing, to the end of the milking period of the ewe). Heritabilities of this trait are 0.25 (in Spanish breeds) and 0.30 (in French ones). Daughter yield deviations (DYD; VanRaden and Wiggans, 1991), as well as weights in the form of equivalent daughter deviations (EDC hereinafter) were computed from regular genetic evaluations. Breed evaluations are done separately (in Spain) or jointly (in France). However, because almost no genealogical connections or multi-breed herds exist, this results in separate evaluations in France as well. Genetic evaluations were verified for lack of bias according to Interbull methods (Boichard et al., 1995) and found to be only slightly biased in the case of France (possibly due to the difficulty of correctly defining contemporary groups) but biased in the Spanish case. The later bias basically shows a difficulty to correctly estimate the average genetic value of rams entering progeny test or, in other words, the genetic trend in absence of progeny-testing data. The reason for this is the use of unknown parent groups (Quaas, 1988) due to unknown fathers, that are more common in Latxa (around 50\% of sheep born in 2009) than in Manech/ 
Table 1. Number of rams, years spanned, and distribution across categories

\begin{tabular}{|c|c|c|c|c|c|c|c|}
\hline \multirow[b]{2}{*}{ Breed $^{1}$} & \multicolumn{4}{|c|}{ Rams in training set, AI progeny tested } & \multicolumn{3}{|c|}{$\begin{array}{c}\text { Rams in validation, genotyped, AI } \\
\text { progeny tested }\end{array}$} \\
\hline & $\begin{array}{l}\text { No. } \\
\text { genotyped }\end{array}$ & $\begin{array}{l}\text { No } \\
\text { nongenotyped }\end{array}$ & $\begin{array}{l}\text { Birth } \\
\text { years }\end{array}$ & $\begin{array}{l}\text { Average } \\
\text { EDC }^{2}\end{array}$ & $\begin{array}{l}\text { No. } \\
\text { genotyped }\end{array}$ & $\begin{array}{l}\text { Birth } \\
\text { years }\end{array}$ & $\begin{array}{l}\text { Average } \\
\text { EDC }\end{array}$ \\
\hline $\mathrm{BB}$ & 194 & 656 & $1990-2005$ & 77 & 87 & $2006-2007$ & 41 \\
\hline MTN & 306 & 255 & 1990-2006 & 88 & 56 & $2007-2008$ & 35 \\
\hline MTR & 1,002 & $2,430^{3}$ & $1990-2006$ & 85 & 293 & $2007-2008$ & 46 \\
\hline LCNEUS & 144 & 1,281 & 1984-2007 & 51 & 51 & 2008-2009 & 13 \\
\hline LCR & 148 & 1,067 & $1984-2007$ & 35 & 47 & 2008-2009 & 25 \\
\hline LCNNAF & 67 & 435 & 1984-2007 & 30 & 24 & 2008-2009 & 17 \\
\hline
\end{tabular}

Basco-Béarnaise (20\% of unknown fatherhood). Inclusion of unknown parent groups hampers estimation of contemporary groups when a sizeable part of the flock has a missing parent. As information (progeny tests) cumulates, genetic evaluations become unbiased. With these caveats, we created a data set whose characteristics are described in Table 1. Data were split in training and cross-validation according to year of birth; the 2 last cohorts were retained as validation, and the oldest as training. In spite of Interbull recommendations (Mäntysaari et al., 2010; Olson et al., 2011), we used the same data set for deriving DYD of both the training and the validation data sets. The reason is that first-crop accuracies are relatively low (on the order of 0.5-0.7), and DYD in the training data set would have been too inaccurate, in particular for Latxa breeds. In general, this seems to slightly underestimate the benefit of genomic evaluations (Olson et al., 2011).

\section{Genotypes}

Rams were genotyped with the OvineSNP50 BeadChip (Illumina Inc., San Diego, CA). Roughly, the last $10 \mathrm{yr}$ of progeny-tested rams were genotyped for French breeds (from 2000 on for BB and MTR, and from 1996 on for MTN, due to its smaller data size). For the Latxa breeds, and due to the smaller number of rams, all available DNA was used (no frozen semen exists). Quality control consisted in verification of call rate (95\% for French rams and 90\% for Spanish rams), parent-offspring discrepancy based on individual SNP ( $<3 \%$ error for French rams and $<5 \%$ for Spanish), SNP call rate $(>97 \%)$, and Hardy-Weinberg equilibrium (SNP with $P<10^{-6}$ were discarded). Finally, all SNP that were polymorphic in all breeds were retained, resulting in 38,287 markers. As a result, not all rams were genotyped, especially in the Latxa breed, including many contemporaries of genotyped individuals; for this reason, a pseudo-single-step genomic BLUP method was used (see below). A description of genotypes by breed (after quality control) can be found in Table 1, and a graphical depiction of genotyping by year for 2 breeds in Figure 2, to show the high degree of unbalance in the Spanish breeds. For the purposes of descriptive analysis (principal components analysis and conservation of linkage disequilibrium patterns), but not for genomic predictions, we added 3,000 genotypes of the Lacaune breed, financed by the research program Roquefort'in [see Baloche et al. (2014) for a complete description of these genotypes].

Tables 2 and 3 describe the pedigree relationships across and within data sets. It is well known that closeness is important for genetic prediction (whether genomic or pedigree based). In Table 2 , it can be verified that in the French breeds (MTR, MTN, and BB), almost all animals in the validation data set have their sire and maternal grandsire genotyped. This is not necessarily the case in Latxa, where most animals have nongenotyped sires. Pszczola et al. (2011) showed that genomic selection still works in this case (genotyped candidates and nongenotyped training data set) but with less advantage than fully genotyping. In addition, it can be observed that some animals in Latxa have no sire/maternal grand sire in the training data set. This is because they did not pass the minimal threshold for DYD calculation (10 daughters). Removing from the validation data set those animals without sire in the training data set resulted in very slight improvement in genomic predictions (not shown).

\section{Genomic Relationships Across Breeds}

Principal Components Analysis. Preliminary exploration of genotypes involved principal components analysis (e.g., as in Kijas et al., 2009) and conservation of linkage disequilibrium patterns, to quantify existing 
Table 2. Description of pedigree relationships across validation and training data sets

\begin{tabular}{|c|c|c|c|c|c|}
\hline \multirow[b]{2}{*}{ Breed $^{1}$} & \multirow{2}{*}{$\begin{array}{c}\text { Individuals } \\
\text { in validation (no.) }\end{array}$} & \multicolumn{2}{|c|}{ With sire in training (no.) } & \multicolumn{2}{|c|}{$\begin{array}{l}\text { With maternal grand sire in training } \\
\text { (no.) }\end{array}$} \\
\hline & & Genotyped & Nongenotyped & Genotyped & Nongenotyped \\
\hline $\mathrm{BB}$ & 87 & 62 & 25 & 57 & 25 \\
\hline MTN & 56 & 56 & 0 & 41 & 14 \\
\hline MTR & 293 & 283 & 10 & 225 & 65 \\
\hline LCNEUS & 51 & 10 & 40 & 11 & 36 \\
\hline LCR & 47 & 13 & 32 & 8 & 32 \\
\hline LCNNAF & 24 & 3 & 19 & 3 & 14 \\
\hline
\end{tabular}

relationships across breeds. The principal components analysis seeks different origins (McVean, 2009) and was applied to several breeds of sheep by Kijas et al. (2009). We applied principal components analysis on the VanRaden (2008) matrix of genomic relationships, which was computed as $\mathbf{G}=\mathbf{Z} \mathbf{Z}^{\prime} / 2 \Sigma p_{i} q_{i}$, where $\mathbf{Z}$ is a matrix of centered genotypes and $p_{i}=1-q_{i}$ is the allelic frequency for the $i$ th marker based on observed genotypes.

Conservation of Linkage Disequilibrium Patterns Across Breeds. We used the correlation statistic suggested by de Roos et al. (2008) and later used by Gibbs et al. (2009) to ascertain the structure of bovine breeds. The pattern of linkage disequilibrium across markers within 1 breed (say breed 1) is fully described by the set of correlations of genotypes (Hill and Robertson, 1968) across all possible pairs of SNP loci [i.e., $\left.\mathrm{r}_{i j \text { breed } 1}=\operatorname{corr}\left(\mathbf{Z}_{\text {breed } 1, i}, \mathbf{Z}_{\text {breed } 1, j}\right)\right]$ for loci $i$ and $j$. Then, for a pair of breeds (breed1 and breed2), we computed the statistic $\rho=\operatorname{corr}\left(\mathrm{r}_{i j, \text { breed } 1}, \mathrm{r}_{i j, \text { breed } 2}\right)$, where the correlation is computed across all pairs of SNP within a certain physical distance. The smaller the distance, the longer the time span described by $\rho$ (Sved, 1971; Tenesa et al., 2007). Values of $\rho$ close to 1 indicate identical patterns of linkage disequilibrium. Ranges of distance to compute $\rho$ were $<10,10$ to 50,50 to 100 , and 100 to $250 \mathrm{~kb}$.

Genomic Inbreeding and Relationships Across Breeds. The $\mathbf{G}$ matrix was again computed as above, but with Lacaune individuals excluded to avoid overrepresentation of their allelic frequencies. Using this $\mathbf{G}$, we computed average self- and across-individual relationships within and across breeds, as in VanRaden et al. (2011). Then, we scaled them, adding a constant so that the lowest relationship would be 0 .

\section{Genomic and Pedigree Evaluations}

We used a single-step genomic BLUP (SSGBLUP; Aguilar et al., 2010; Christensen and Lund, 2010) but applied to male DYD [e.g., as in Su et al. (2012)]. We will call this the pseudo-SSGBLUP as opposed to regular animal-model single step. We extended this method to the multiple-trait method of Karoui et al. (2012), which considers each breed as a different trait. The linear model was, therefore, as follows:

$$
\begin{aligned}
& \mathbf{y}=\mathbf{X b}+\mathbf{W u}+\mathbf{e} \\
& \operatorname{Var}(\mathbf{u})=\mathbf{H} \otimes \mathbf{G}_{0} \\
& \operatorname{Var}(\mathbf{e})=\mathbf{F} \otimes \mathbf{R}_{0}
\end{aligned}
$$

where vector $\mathbf{y}$ contains DYD twice for each ram (no ram has DYD in 2 different breeds), vector $\mathbf{b}$ contains within-breed general means (each animal is uniquely

Table 3. Description of pedigree relationships within the validation data set (data are number of sheep in each category)

\begin{tabular}{lcccc}
\hline Breed $^{1}$ & $\begin{array}{c}\text { Number of } \\
\text { individuals }\end{array}$ & $\begin{array}{c}\text { Unique paternal } \\
\text { full-sib families (no.) }\end{array}$ & $\begin{array}{c}\text { Unique } \\
\text { half-sib families (no.) }\end{array}$ & Sons/sire (no.) \\
\hline BB & 87 & 86 & 24 & 3.63 \\
MTN & 56 & 56 & 18 & 3.11 \\
MTR & 293 & 292 & 55 & 5.33 \\
LCNEUS & 51 & 48 & 13 & 3.92 \\
LCR & 47 & 42 & 22 & 2.14 \\
LCNNAF & 24 & 21 & 12 & 2.00
\end{tabular}

${ }^{1} \mathrm{BB}=$ Basco-Béarnaise; MTN = Manech Tête Noire; MTR = Manech Tête Rousse; LCNEUS = Latxa Cara Negra Euskadi; LCR: Latxa Cara Rubia; LCNNAF = Latxa Cara Negra Navarre. 
defined in a breed, opposite to Makgahlela et al., 2013), vector $\mathbf{u}$ is a vector of ram breeding values, $\mathbf{e}$ is a vector of residuals, $\mathbf{X}$ and $\mathbf{W}$ are incidence matrices, $\mathbf{G}_{0}$ is a matrix of genetic covariances across traits, $\mathbf{F}$ is a diagonal matrix with inverses of weights (EDC), and $\mathbf{R}_{0}$ is a diagonal matrix with residual variances $\sigma_{e i}^{2}$ for the $i$ th breed, which were constructed from within-breed pedigree-based estimates as $\sigma_{e i}^{2}=2 \sigma_{u i}^{2}+4 \sigma_{e i}^{2}$, where $\sigma_{u i}^{2}$ is the genetic variance and $\sigma_{e i}^{2}$ is the residual variance. Therefore, every breed is a different trait for milk yield. Matrix $\mathbf{H}$ is the joint pedigree-genomic matrix described by Legarra et al. (2009) and Christensen and Lund (2010), including genomic relationships, and with the $\mathrm{F}_{\mathrm{ST}}$-based corrections described by Vitezica et al. (2011), where $\mathrm{F}_{\mathrm{ST}}$ is the mean relationship between gametes in a recent population with respect to an older base population. This correction was applied crudely (i.e., no account was made of the different subpedigrees or breed origins). A finer correction would have included within- and across-population terms, as in Harris and Johnson (2010), but the theory for a multiplebreed scenario in the context of the single step has not been developed yet. Genetic parameter matrix $\mathbf{G}_{0}$ was constructed with pedigree-based estimates $\sigma_{u i}^{2}$ in the diagonal. Off-diagonal elements made the difference between within-population predictions or pooled predictions, as described next.

Single-Breed Predictions. In this case, off-diagonal elements of $\mathbf{G}_{0}$ were set to zero. This resulted in
6 separate genetic evaluations because no covariances across individuals or records in different populations existed.

Multi-Breed Pooled Predictions. These were computed fitting appropriate off-diagonal values in $\mathbf{G}_{0}$ (i.e., considering the SNP effects as correlated from one population to the other). However, for the final studies not all breeds were pooled together. Two multiple-breed predictions were tested. In the first one, we pooled MTR and LCR (blond populations). In the second one, we pooled MTN and LCNNAF populations (black closely related breeds). Records from BB and LCNEUS were not included in multiple-breed predictions, because BB is an isolated population and because serious doubts exist about the quality of DYD in the LCNEUS, as will be shown later. We tried several values for the across-breed genetic correlations in $\mathbf{G}_{0}$. Some analyses fitted ad hoc genetic correlations of 0.95 (e.g., almost identical traits). In other analyses, we estimated the genetic correlations in $\mathbf{G}_{0}$ using available data. Instead of a complete REML analysis, we ran a grid search for genetic correlations from 0 to 0.99 , with a step of 0.1 and picked the one maximizing the residual likelihood. This genetic correlation is explained by genetic drift between populations and also by genotype $\times$ environment interactions, including possibly different management systems, slightly different performance recording, climate, and so on.

For the pedigree-based evaluation, only pedigreebased relationships (A) were used instead of $\mathbf{H}$ and
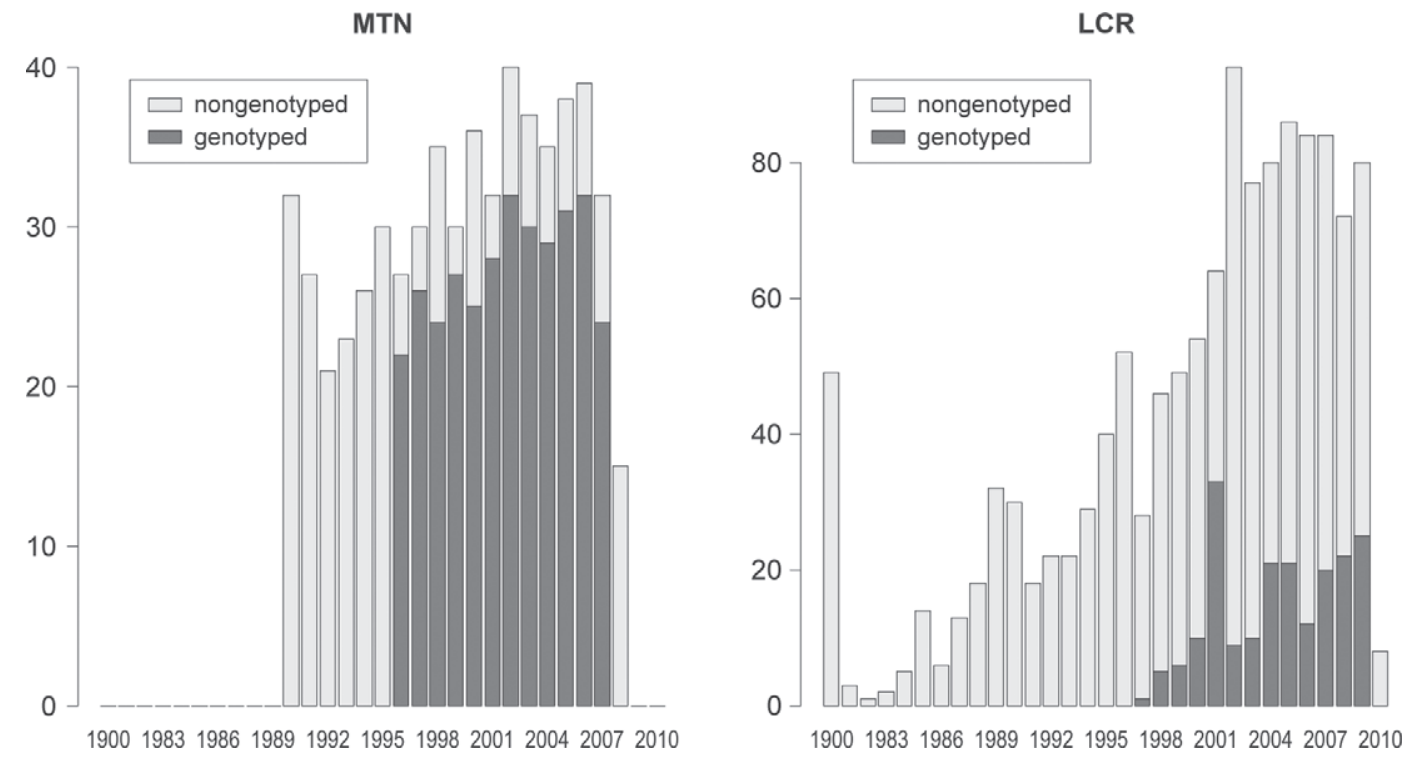

Figure 2. Distribution of genotypes of rams in the training data set across years for 2 breeds: Manech Tête Noire (MTN) and Latxa Cara Rubia (LCR). 
off-diagonal elements of $\mathbf{G}_{0}$ were set to zero (setting them to genetic correlations of 0.95 resulted in almost the same results; pedigree connections across Spanish populations exist but are tiny). Program PreGSf90 (Aguilar et al., 2011) was used for construction of $\mathbf{G}$ and iteration on data (program blup90iod2; Tsuruta et al.; 2001) to solve mixed-model equations.

\section{Goodness of Prediction}

Statistics of goodness of prediction were the accuracy or correlation $R$ between predicted and progeny-tested EBV (TEBV), and bias and slope, defined as $b_{0}$ and $b_{1}$ in the linear regression TEBV $=b_{0}+b_{1} \mathrm{EBV}+\mathbf{e}$, where $\mathbf{e}$ is a vector with residuals (Mäntysaari et al., 2010). Bias defines the capacity to predict average value of candidates to selection (i.e., genetic trend) and slope the overdispersion of EBV (for values lower than 1). The correlation was corrected using $R_{\text {validation }}=R(\mathrm{EBV}, \mathrm{TEBV}) \sqrt{1+k / \overline{\mathrm{EDC}}}$, with $k=$ $\left(4-\mathrm{h}^{2}\right) / \mathrm{h}^{2}$ (Mäntysaari et al., 2010).

Because validation data sets are small and selected, they are very idiosyncratic; we wanted to correctly ascertain the error in these statistics, which might be, for instance, sensible to extreme values of TEBV or EBV. We implemented a bootstrap procedure that sampled with replacement candidates to selection and computed $R, b_{0}$, and $b_{1}$. The procedure was run 1,000 times.

\section{RESULTS}

\section{Genetic Similarities Across Breeds}

Principal Components Analysis. The projection of each individual on the 2 main principal components is shown in Figure 3. The 2 first principal components of $\mathbf{G}$ explain only 5.22 and $1.48 \%$ of the covariance across individuals. It can be seen that the first axis distinguishes Lacaune from Western Pyrenees populations, whereas the second one distinguishes across Pyrenees populations and also the 2 Lacaune subschemes. The differentiation within Pyrenees is clearly geographical for the BB and MTN breeds and both Latxa Cara Negra strains, which are located following a top-down (in Figure 3) east-to-west (geographically) pattern. It can be verified as well that LCNNAF is connected to both MTN and LCNEUS, whereas the latter 2 are hardly connected. This agrees with previous knowledge as described in the Introduction section. As for the MTR and LCR, they largely overlap, as a result of the frequent recent exchanges.

Conservation of Linkage Disequilibrium Patterns. This is shown in the form of heat maps, which is a graphical presentation of correlations, in Figures 4 and 5. Each figure presents result for SNP at a certain physical distance. The figures show the same patterns of relationships as the principal components analysis. Both Lacaune subschemes, as well as LCR and MTR, are strongly related. Breed BB is clearly isolated, whereas MTN and both Latxa Cara Negra strains are mildly linked. The pattern is consistent across the 4 sets of distances among the SNP studied (results for $10-50 \mathrm{~kb}$ and $50-100 \mathrm{~kb}$ are not shown). Values are similar to those reported for cattle breeds. For instance, the correlation between LCR and MTR or across the 2 Lacaune schemes is lower than that between Red Angus and Angus, and comparable with that between Holstein and Nordic Red Cattle (Gibbs et al., 2009). Therefore, it is hard to consider any of those pairs as the same population. The correlation between Lacaune and any Pyrenean breed is similar to that between Jersey and Holstein (Gibbs et al., 2009).

Genomic Inbreeding and Relationships Across Breeds. The lowest average genomic relationship was among BB and MTR breeds (as expected, for example, from Figure 3), with a value of -0.028 . We added this value to all average genomic relationships and genomic inbreeding, with results given in Table 4. Relationships follow the pattern of the 2 previous paragraphs: blond breeds and black breeds are related, with BB more isolated. As for inbreeding, this estimate of inbreeding is relative to the allelic frequencies of the pool of breeds, where MTR predominates. Hence, this breed

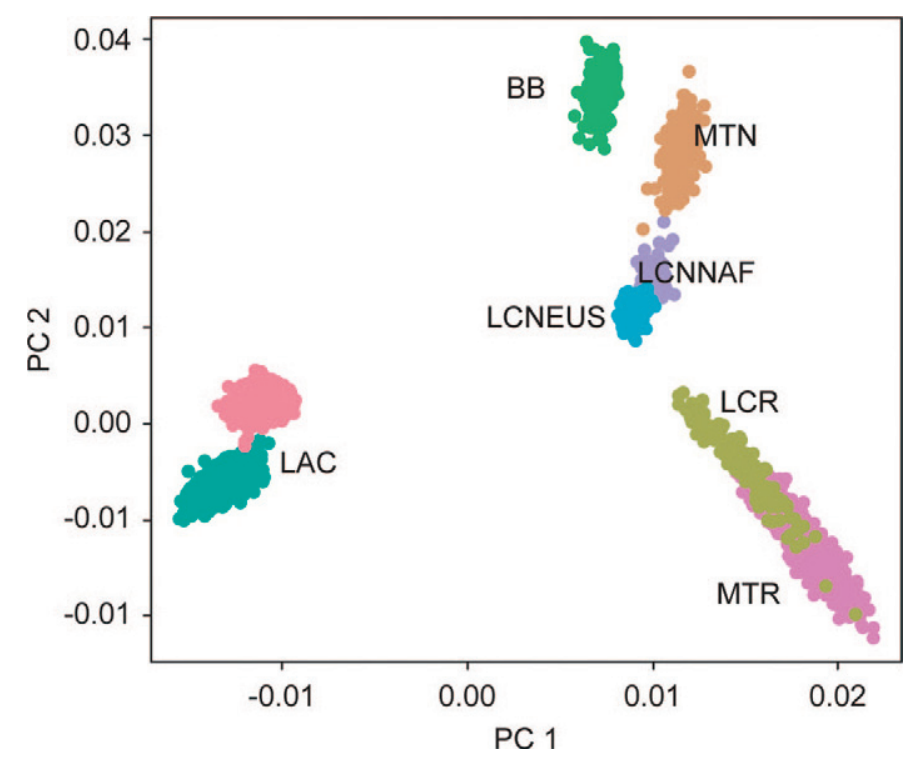

Figure 3. Principal components (PC) analysis (2 axis) showing the location of Basco-Béarnaise (BB), Lacaune (LAC), Manech Tête Noire (MTN), Manech Tête Rousse (MTR), Latxa Cara Rubia (LCR), Latxa Cara Negra Navarra (LCNNAF), and Latxa Cara Negra Euskadi (LCNEUS). Color version available in the online PDF. 

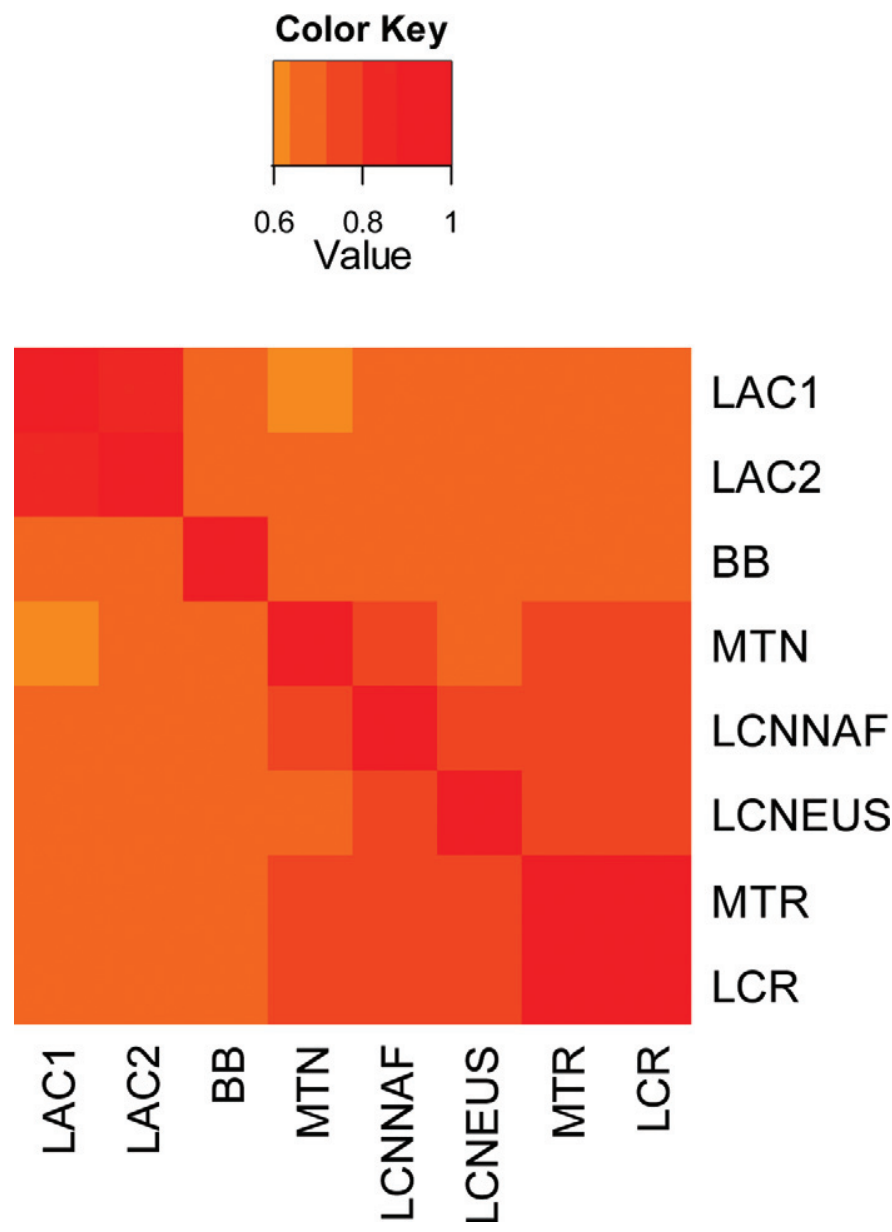

MTR

LCR

Figure 4. Heat map of conservation across breeds of linkage disequilibrium patterns across pairs of SNP at distances of less than 10 kb. LAC = Lacaune; $\mathrm{BB}=$ Basco-Béarnaise; $\mathrm{MTN}=$ Manech Tête Noire; LCNNAF = Latxa Cara Negra Navarra; LCNEUS = Latxa Cara Negra Euskadi; MTR = Manech Tête Rousse; LCR = Latxa Cara Rubia. Color version available in the online PDF.

shows little inbreeding, whereas BB (the least related to MTR) shows higher inbreeding.

\section{Genomic and Pedigree Evaluations}

Single-Breed Predictions. Predictions for animals in the training data set (not shown) were basically exact (correlation >0.99) and unbiased, as expected. Results for animals in the validation data set are shown in Table 5. It was verified that, in general, the accuracy of pedigree information could be quite low, even being negative. The reason is that we tried to rank a set of selected animals, which is notoriously more difficult than ranking unselected individuals (Bijma, 2012; for instance, pedigree information cannot rank full-sibs). In any case, the genomic evaluation was generally more accurate than the pedigree-based one, in absolute
Color Key
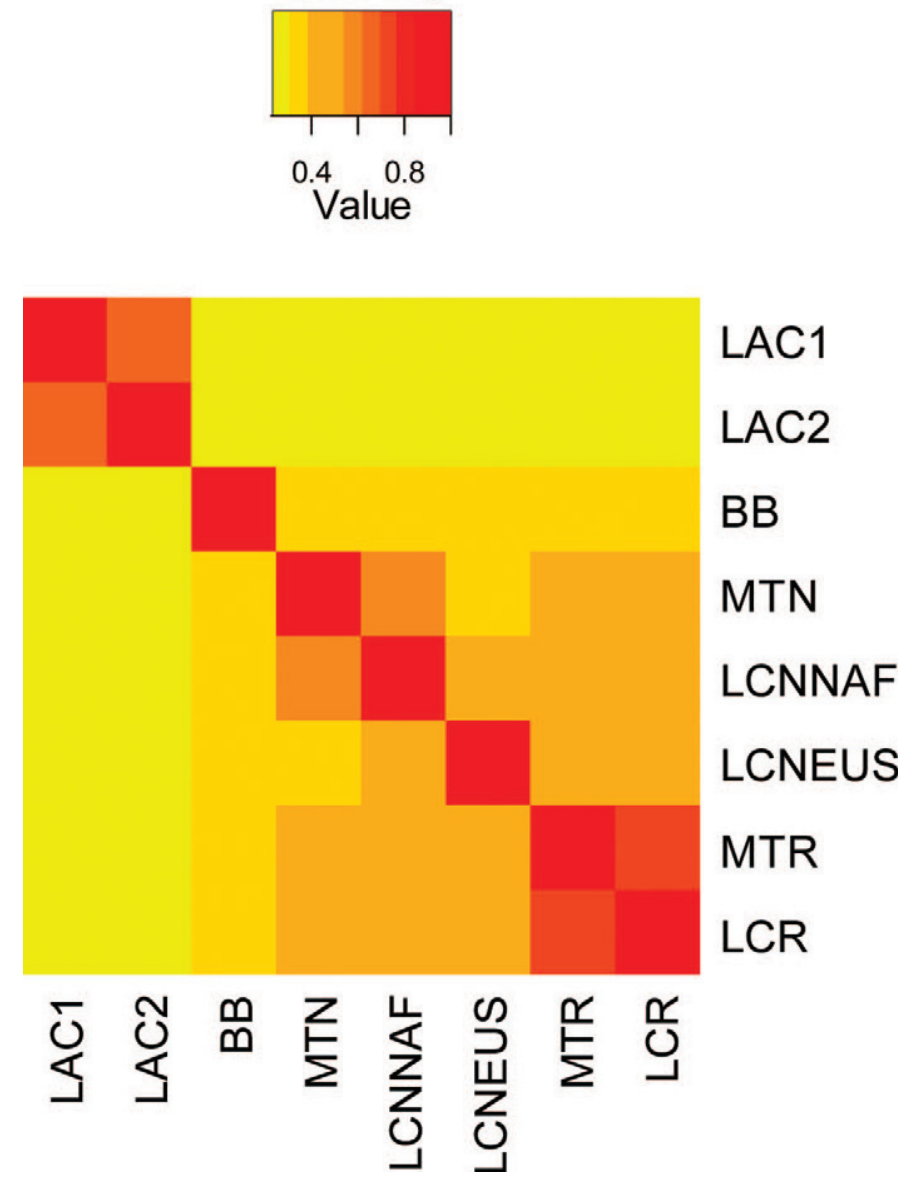

Figure 5. Heat map of conservation across breeds of linkage disequilibrium patterns across pairs of SNP at distances of less than 100 to $250 \mathrm{~kb}$. LAC = Lacaune; $\mathrm{BB}=$ Basco-Béarnaise; MTN = Manech Tête Noire; LCNNAF = Latxa Cara Negra Navarra; LCNEUS = Latxa Cara Negra Euskadi; MTR = Manech Tête Rousse; LCR = Latxa Cara Rubia. Color version available in the online PDF.

value, with the exception of the LCNEUS breed (this exception is consistent across different partitioning of validation data sets or removal of some animals). A possible but hard-to-verify explanation is that an underlying bias exists in the routine genetic evaluations, which causes this strange result.

As for the increase in accuracy due to the use of genotypes, if we except LCNEUS, it ranged between 0.05 and 0.30 , yet (according to bootstrap results); this extra accuracy was significant only for LCR and MTR $(P<0.05)$. The rest of values were too variable to be seriously trusted.

In addition, it was verified that slopes of the regression were closer to 1 with genomic information (if we excluded LCNEUS), although MTN and LCR were still far from a slope of 1 . Values closer to 1 indicate less overdispersion of breeding values. Also, the bias is 
Table 4. Average genomic relationships across breeds and inbreeding, after scaling the lowest relationship to 0

\begin{tabular}{lcccccc}
\hline Breed $^{1}$ & BB & MTN & MTR & LCNEUS & LCR & LCNNAF \\
\hline BB & 0.232 & & & & & \\
MTN & 0.038 & 0.198 & & & & \\
MTR & 0.000 & 0.005 & 0.070 & & & \\
LCNEUS & 0.050 & 0.050 & 0.020 & 0.159 & 0.085 & \\
LCR & 0.021 & 0.023 & 0.045 & 0.040 & 0.187 \\
LCNNAF & 0.050 & 0.091 & 0.019 & 0.066 & 0.037 & 0.088 \\
Inbreeding & 0.129 & 0.086 & 0.000 & 0.094 & 0.036 & \\
\hline
\end{tabular}

${ }^{1} \mathrm{BB}=$ Basco-Béarnaise; MTN = Manech Tête Noire; MTR = Manech Tête Rousse; LCNEUS = Latxa Cara Negra Euskadi; LCR: Latxa Cara Rubia; LCNNAF = Latxa Cara Negra Navarre.

reduced: genomic predictions estimate more correctly the average value of the EBV of the candidates; hence, it estimates better the genetic trend and makes young animals and progeny-tested ones more comparable. Histograms of the distribution of the different statistics are shown in Figure 6. These distributions are not skewed but the large confidence intervals can be observed.

In general, French breeds showed a more consistent behavior than Spanish ones; this is likely due to more data, the better quality of the French routine genetic evaluation, and also of the balanced distribution of genotypes across the population.

Multiple-Breed Pooled Predictions. The genetic correlations between breeds were estimated as 0.5 between LCR and MTR and as 0.3 between MTN and LCNNAF. Results of predictions are presented in Table 6. Other values of genetic correlations were tried but the results did not change much; in particular, setting the genetic correlations to the estimated value did not increase predictive abilities. Comparing accuracies in
Table 6 with those of Table 5 , it can be observed that the accuracies of blond breeds (LCR and MTR) did not change (and did not improve) whether the prediction was single breed or multiple breed. This is in spite of their strong connections, although at this moment, none of the LCR candidates is the son of an MTR training sire (at most, they are grandsons). However, both MTN and LCNNAF benefitted (not significantly) from pooling the data (genomic accuracies in Table 6 are higher than in Table 5). This was unexpected in view of their remote connections and we speculate that this is more an effect of an overall improvement in the fit of the linear model (in view of the scarcity of data for both breeds) than a real improvement based on genetics of both breeds. For instance, combining both breeds would increase shrinkage in the predictions, which provides higher accuracies, even if this phenomenon does not respond to true genetic factors.

As a complement, we tried a full 6-population prediction with genetic correlations of 0.95 across all breeds,

Table 5. Bias, slope, and accuracy $\pm \mathrm{SE}$ (obtained by bootstrap) of single-breed pedigree and genomic evaluations of milk yield, and their difference (genomic - pedigree)

\begin{tabular}{|c|c|c|c|c|}
\hline Breed $^{1}$ & Model & $\operatorname{Bias}^{2}$ & Slope & Accuracy \\
\hline \multirow[t]{3}{*}{$\mathrm{BB}$} & Pedigree & $4.92 \pm 7.52$ & $0.95 \pm 0.25$ & $0.46 \pm 0.12$ \\
\hline & Genomic & $0.80 \pm 8.19$ & $1.07 \pm 0.28$ & $0.52 \pm 0.10$ \\
\hline & Genomic - pedigree & $-4.41 \pm 4.39$ & $0.13 \pm 0.14$ & $0.06 \pm 0.07$ \\
\hline \multirow[t]{3}{*}{ MTN } & Pedigree & $14.43 \pm 12.37$ & $0.44 \pm 0.41$ & $0.16 \pm 0.14$ \\
\hline & Genomic & $10.51 \pm 10.01$ & $0.56 \pm 0.33$ & $0.28 \pm 0.14$ \\
\hline & Genomic - pedigree & $-4.35 \pm 8.87$ & $0.14 \pm 0.30$ & $0.11 \pm 0.11$ \\
\hline \multirow[t]{3}{*}{ MTR } & Pedigree & $16.98 \pm 8.64$ & $0.66 \pm 0.18$ & $0.29 \pm 0.08$ \\
\hline & Genomic & $7.89 \pm 6.09$ & $0.83 \pm 0.13$ & $0.43 \pm 0.06$ \\
\hline & Genomic - pedigree & $-9.37 \pm 6.87$ & $0.18 \pm 0.15$ & $0.16 \pm 0.06$ \\
\hline \multirow{3}{*}{ LCNEUS } & Pedigree & $57.47 \pm 27.94$ & $0.33 \pm 0.28$ & $0.34 \pm 0.28$ \\
\hline & Genomic & $70.54 \pm 32.02$ & $0.19 \pm 0.32$ & $0.19 \pm 0.31$ \\
\hline & Genomic - pedigree & $14.77 \pm 15.38$ & $-0.15 \pm 0.16$ & $-0.18 \pm 0.13$ \\
\hline \multirow[t]{3}{*}{ LCR } & Pedigree & $145.81 \pm 51.72$ & $-0.08 \pm 0.39$ & $-0.05 \pm 0.26$ \\
\hline & Genomic & $91.05 \pm 36.72$ & $0.33 \pm 0.27$ & $0.26 \pm 0.20$ \\
\hline & Genomic - pedigree & $-50.34 \pm 29.12$ & $0.37 \pm 0.22$ & $0.30 \pm 0.13$ \\
\hline \multirow[t]{3}{*}{ LCNNAF } & Pedigree & $23.68 \pm 8.61$ & $0.73 \pm 0.47$ & $0.43 \pm 0.28$ \\
\hline & Genomic & $17.93 \pm 10.19$ & $0.88 \pm 0.46$ & $0.48 \pm 0.25$ \\
\hline & Genomic - pedigree & $-5.00 \pm 4.54$ & $0.12 \pm 0.25$ & $0.04 \pm 0.14$ \\
\hline
\end{tabular}

${ }^{1} \mathrm{BB}=$ Basco-Béarnaise; MTN = Manech Tête Noire; MTR = Manech Tête Rousse; LCNEUS = Latxa Cara Negra Euskadi; LCR: Latxa Cara Rubia; LCNNAF = Latxa Cara Negra Navarre.

${ }^{2}$ In liters. Positive number means underestimation of EBV. Typically, validation is underestimated. 
Table 6. Bias, slope, and accuracy \pm SE (obtained by bootstrap) of 2 multiple-breed pedigree and genomic evaluations [Manech Tête Rousse (MTR) with Latxa Cara Negra Euskadi (LCR); Manech Tête Noire (MTN) with Latxa Cara Negra Navarre (LCNNAF)] of milk yield, and their difference (genomic - pedigree)

\begin{tabular}{|c|c|c|c|c|}
\hline Breed & Model & $\operatorname{Bias}^{1}$ & Slope & Accuracy \\
\hline \multirow[t]{3}{*}{ MTN } & Pedigree & $14.43 \pm 12.37$ & $0.44 \pm 0.41$ & $0.16 \pm 0.15$ \\
\hline & Genomic & $7.99 \pm 9.65$ & $0.62 \pm 0.30$ & $0.33 \pm 0.14$ \\
\hline & Genomic - pedigree & $-7.03 \pm 8.93$ & $0.20 \pm 0.30$ & $0.18 \pm 0.11$ \\
\hline \multirow[t]{3}{*}{ MTR } & Pedigree & $16.98 \pm 8.64$ & $0.66 \pm 0.18$ & $0.29 \pm 0.08$ \\
\hline & Genomic & $7.89 \pm 6.09$ & $0.83 \pm 0.13$ & $0.43 \pm 0.06$ \\
\hline & Genomic - pedigree & $-9.37 \pm 6.87$ & $0.18 \pm 0.15$ & $0.16 \pm 0.06$ \\
\hline \multirow[t]{3}{*}{ LCR } & Pedigree & $145.81 \pm 51.72$ & $-0.08 \pm 0.39$ & $-0.05 \pm 0.20$ \\
\hline & Genomic & $94.01 \pm 37.49$ & $0.31 \pm 0.32$ & $0.25 \pm 0.22$ \\
\hline & Genomic - pedigree & $-47.53 \pm 27.71$ & $0.35 \pm 0.21$ & $0.29 \pm 0.14$ \\
\hline \multirow[t]{3}{*}{ LCNNAF } & Pedigree & $23.68 \pm 8.61$ & $0.73 \pm 0.47$ & $0.43 \pm 0.28$ \\
\hline & Genomic & $17.42 \pm 10.11$ & $0.93 \pm 0.47$ & $0.51 \pm 0.26$ \\
\hline & Genomic - pedigree & $-5.54 \pm 4.27$ & $0.17 \pm 0.23$ & $0.06 \pm 0.12$ \\
\hline
\end{tabular}

${ }^{1}$ In liters. Positive means underestimation of EBV. Typically, validation is underestimated.

but results (not shown) were qualitatively very similar (i.e., slight improvement for MTN and LCNNAF as above, and no improvement for BB or LCNEUS).

\section{DISCUSSION}

We used 3 ways of ascertaining the connection between 2 populations. Principal components analysis ordered populations correctly, but was unable to quantify absolutely the relatedness of 2 given populations, as the figures we obtained referred to the set of populations analyzed. Nevertheless, it is very useful in providing a visual idea of relationships across populations and for other tasks such as finding mislabeled samples. Concordance of linkage disequilibrium, although less impressive, gave absolute figures that could be compared [e.g., against Gibbs et al. (2009) results in taurine breeds]. This allowed us to ascertain that, for instance, the 2 Lacaune strains or MTR and LCR are not as related as we may have thought and, therefore, pooling both populations for genomic predictions was a priori less interesting, as confirmed in the present work for MTR/ LCR and in Lacaune by Baloche et al. (2014). As for genomic inbreeding and relationships across breeds, they agreed with the overall picture. It has to be kept in mind, though, that genomic inbreeding reflects deviation of genotypes from Hardy-Weinberg equilibrium, assuming the frequencies in the overall population. Hence, BB seemed most inbred only because its frequencies deviated most from the overall population.

In general, increased accuracy of genomic evaluations existed over pedigree-based ones. This increase was lower than values reported in Holstein dairy cattle (e.g., VanRaden et al., 2009), but the absolute numbers are comparable with small dairy cattle breeds such as Montbéliarde (Colombani et al., 2013) and to the values in Lacaune dairy sheep, which were $0.32,0.43$, and
0.47 for milk yield evaluations based on BLUP, pseudoSSGBLUP, and SSGBLUP, respectively (Baloche et al., 2014). Models used in the current study are not the most efficient; SSGBLUP shows higher accuracies and will be tested within breed with the full data sets. In addition, if DYD are generated with bias due to the inclusion of unknown parent groups (i.e., younger rams are over- or underestimated due to the inability to reflect the genetic trend) this bias will be transmitted forward to genomic predictions. Single-step genomic BLUP can include unknown parent groups (Misztal et al., 2013) and this research is planned in these breeds.

The puzzling behavior of the LCNEUS breed has no clear explanation to us, because it has no clear distinct features from any other Latxa breed, either in constitution of the population or in handling of phenotypic, pedigree, or marker data.

Concerning accuracy, in Table 3 , it can be verified that animals in the validation data set did not form large paternal sibships. This contrasts with dairy cattle. This may explain part of the lower gain in accuracy. In large sibships, genomic selection is expected to perform very well, because it is able to differentiate which of the chromosomes of the sire the candidate has received.

The results of this work confirm the well-documented inability of genomic predictions to perform well across distant populations or even families (Habier et al., 2007, 2010; Legarra et al., 2008). In fact, the only cases where the interest of an across-population genetic evaluation has been clearly shown are those where the populations interbreed often so that they can be considered as a single population [for instance, Holsteins (VanRaden et al., 2009; Lund et al., 2011) or Brown Swiss (Jorjani et al., 2012)]. The rest of cases where an interest exists across breeds contain, in most cases, traits with large QTL such as DGAT1 [e.g., Hayes et al. (2009); Erbe et al. (2012); see Karoui et al. (2012) for a clear example]. 

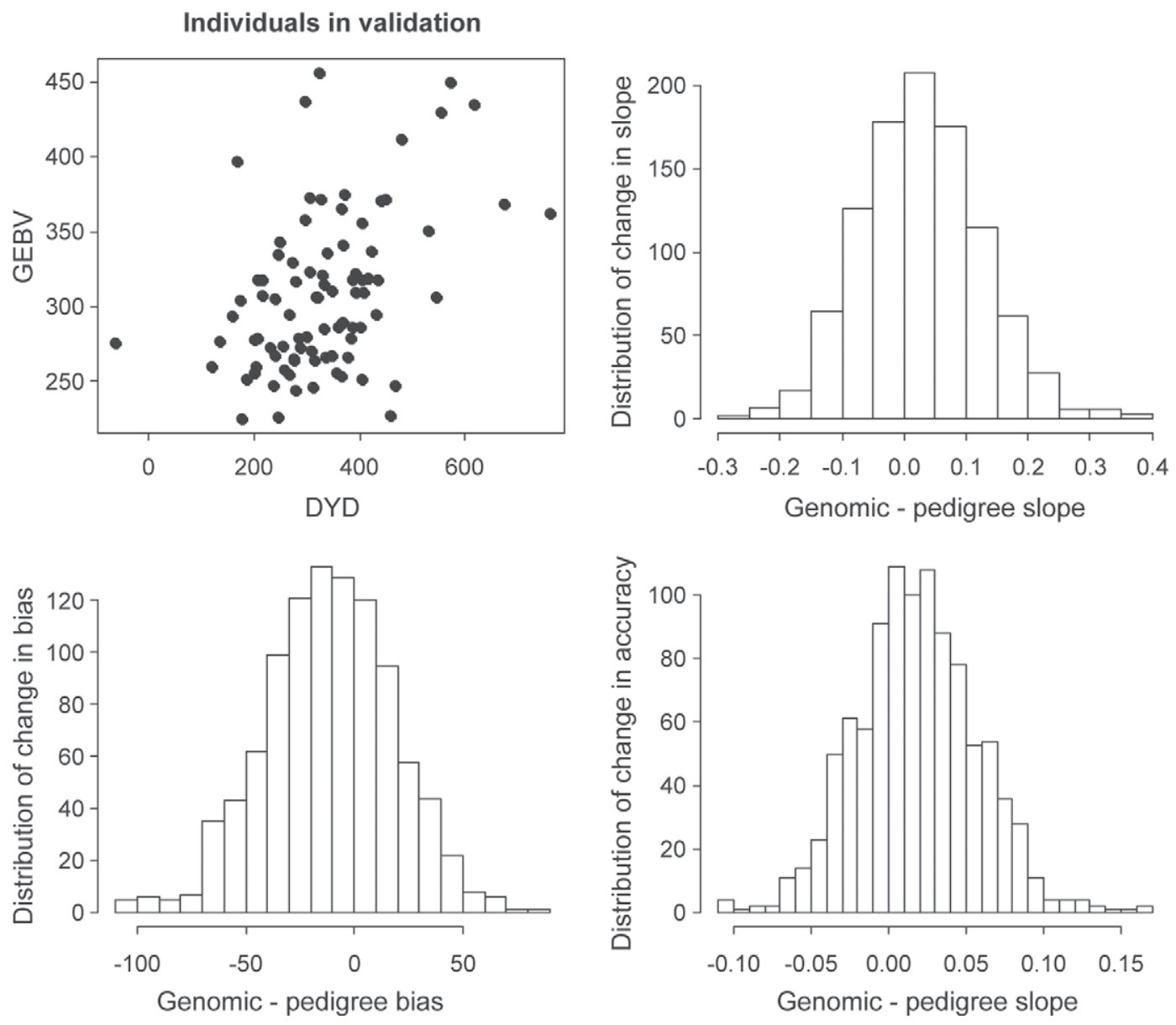

Figure 6. Results of the cross-validation analysis in Basco-Béarnaise. Genomic predictions [genomic EBV (GEBV)] versus observed daughter yield deviations (DYD) and (bootstrap) distribution of change in slope, bias, and accuracy from pedigree predictions to genomic predictions.

We have also quantified genomic relationships across breeds using genetic correlations (Karoui et al., 2012). This reflects, at the same time, genetic divergence of the breeds and genotype by environment interaction. Correlations are trait dependent (e.g., Karoui et al., 2012). Estimated correlations were actually low (maximum of 0.5 between LCR and MTR), whereas Karoui et al. (2012) estimated correlations of up to 0.8 between 2 genealogically more distant populations (Montbéliarde and Holstein) due possibly to an old introgression of DGAT1 in Montbéliardes. Our results do not imply that genetic improvement in MTR would not work in the LCR environment: indeed, results by Ugarte et al. (1996) showed the value of MTR rams in the LCR population, and their results are confirmed periodically.

An interesting result in our work was the good behavior of the BB breed. It showed a good pedigree-based accuracy (0.41) and an even better (0.46) genomic one, and the evaluations were unbiased. This result was obtained in spite of a small training population, including 194 genotyped rams in addition to 656 ungenotyped ones. This population size is much lower than most recommendations found in the literature. This outcome is possibly due to 2 reasons: a very serious progenytesting data set (unbiased, as can be seen), and a closed population, so that candidates to selection have information from almost all relatives. We need to point out that the pseudo-single-step evaluation was needed to achieve these accuracies; a genomic BLUP with only the 194 genotyped individuals did not perform better than pedigree predictions.

An open question is the future genomic improvement of these breeds. Although our results showed the increased accuracy value of single-breed genomic predictions with not always very large populations (such as MTR and BB), this increase was not large and the costs of genotyping are high. Optimized breeding programs (e.g., Thomasen et al., 2014) can be designed that make use of technologies such as imputation or parentage assignment to reduce costs and constraints. Other possibilities would consider fusion of populations to have economy scales and higher accuracies. This op- 
tion would face legal and sanitary constraints because of 2 different countries involved.

\section{CONCLUSIONS}

We have shown that dairy sheep breeds in the Western Pyrenees are structured according to known exchanges across breeds. These exchanges are not enough to consider any group of several breeds as a single breeding population. From the point of view of increased accuracy, little interest exists in pooling data from several populations for genomic predictions. However, genomic evaluations are more accurate than pedigree-based ones and foster the interest of genomic selection.

\section{ACKNOWLEDGMENTS}

Major financing for the work came from project GENOMIA, financed by POCTEFA (http://www.poctefa. eu) with European Union Fonds européen de développement régional (FEDER) funds. Lacaune genotypes were financed by Agence Nationale de la Recherche (ANR)SheepSNPQTL, ApisGene (Paris, France), Fonds Unique Interministériel (FUI)-Roquefort'in projects (Midi-Pyrénees region, FEDER), Aveyron and Tarn departments (Midi-Pyrénees region), and the city of Grand Rodez (France). We thank the breeders' associations (CONFELAC in Spain and CDEO and OS ROLP in France) for providing the data, and Ignacy Misztal and Shogo Tsuruta (University of Georgia, Athens) and Ignacio Aguilar [Instituto Nacional de Investigacion Agropecuaria (INIA), Montevideo, Uruguay] for help with the software. Also, we thank Labogena (Jouyen-Josas, France; http://www.labogena.fr) and CIC Biogune (Derio, Spain; http://www.cicbiogune.es) for genotyping. We are grateful to the GenoToul bioinformatics platform Toulouse Midi-Pyrenees for providing computing and storage resources. The maps in Figure 1 were obtained from http://www.openstreetmap.org and are licensed under an Open Data Commons Open Database License. A. Legarra acknowledges financing from X-Gen action of the INRA SelGen metaprogram (Paris, France).

\section{REFERENCES}

Aguilar, I., I. Misztal, D. L. Johnson, A. Legarra, S. Tsuruta, and T. J. Lawlor. 2010. Hot topic: A unified approach to utilize phenotypic, full pedigree, and genomic information for genetic evaluation of Holstein final score. J. Dairy Sci. 93:743-752.

Aguilar, I., I. Misztal, A. Legarra, and S. Tsuruta. 2011. Efficient computations of genomic relationship matrix and other matrices used in the single-step evaluation. J. Anim. Breed. Genet. 128:422-428.

Baloche, G., A. Legarra, G. Sallé, H. Larroque, J. M. Astruc, C. Robert-Granié, and F. Barillet. 2014. Assessment of accuracy of genomic prediction for French Lacaune dairy sheep. J. Dairy Sci. 97:1107-1116.
Barillet, F. 1997. Genetics of milk production. Pages 539-564 in The Genetics of Sheep. L. Piper and A. Ruvinsky, ed. CABI, Wallingford, UK.

Bijma, P. 2012. Accuracies of estimated breeding values from ordinary genetic evaluations do not reflect the correlation between true and estimated breeding values in selected populations. J. Anim. Breed. Genet. 129:345-358.

Boichard, D., B. Bonaiti, A. Barbat, and S. Mattalia. 1995. Three methods to validate the estimation of genetic trend for dairy cattle. J. Dairy Sci. 78:431-437.

Christensen. O. F., and M. S. Lund. 2010. Genomic prediction when some animals are not genotyped. Genet. Sel. Evol. 42:2.

Colombani, C., A. Legarra, S. Fritz, F. Guillaume, P. Croiseau, V. Ducrocq, and C. Robert-Granié. 2013. Application of Bayesian least absolute shrinkage and selection operator (LASSO) and BayesC $\pi$ methods for genomic selection in French Holstein and Montbéliarde breeds. J. Dairy Sci. 96:575-591.

de Roos, A. P. W., B. J. Hayes, R. Spelman, and M. E. Goddard. 2008. Linkage disequilibrium and persistence of phase in Holstein-Friesian, Jersey and Angus cattle. Genetics 179:1503-1512.

Duchemin, S. I., C. Colombani, A. Legarra, G. Baloche, H. Larroque, J.-M. Astruc, F. Barillet, C. Robert-Granié, and E. Manfredi. 2012. Genomic selection in the French Lacaune dairy sheep breed. J. Dairy Sci. 95:2723-2733.

Erbe, M., B. J. Hayes, L. K. Matukumalli, S. Goswami, P. J. Bowman, C. M. Reich, B. A. Mason, and M. E. Goddard. 2012. Improving accuracy of genomic predictions within and between dairy cattle breeds with imputed high-density single nucleotide polymorphism panels. J. Dairy Sci. 95:4114-4129.

García-Gámez, E., B. Gutiérrez-Gil, G. Sahana, J.-P. Sánchez, Y. Bayón, and J.-J. Arranz. 2012. GWA analysis for milk production traits in dairy sheep and genetic support for a QTN influencing milk protein percentage in the $L A L B A$ gene. PLoS ONE 7:e47782.

Gibbs, R. A., J. F. Taylor, C. P. Van Tassell, W. Barendse, K. A. Eversole, C. A. Gill, R. D. Green, D. L. Hamernik, S. M. Kappes, S. Lien, L. K. Matukumalli, J. C. McEwan, L. V. Nazareth, R. D. Schnabel, G. M. Weinstock, D. A. Wheeler, P. Ajmone-Marsan, P. J. Boettcher, A. R. Caetano, J. F. Garcia, O. Hanotte, P. Mariani, L. C. Skow, T. S. Sonstegard, J. L. Williams, B. Diallo, L. Hailemariam, M. L. Martinez, C. A. Morris, L. O. C. Silva, R. J. Spelman, W. Mulatu, K. Zhao, C. A. Abbey, M. Agaba, F. R. Araujo, R. J. Bunch, J. Burton, C. Gorni, H. Olivier, B. E. Harrison, B. Luff, M. A. Machado, J. Mwakaya, G. Plastow, W. Sim, T. Smith, M. B. Thomas, A. Valentini, P. Williams, J. Womack, J. A. Woolliams, Y. Liu, X. Qin, K. C. Worley, C. Gao, H. Jiang, S. S. Moore, Y. Ren, X.-Z. Song, C. D. Bustamante, R. D. Hernandez, D. M. Muzny, S. Patil, A. San Lucas, Q. Fu, M. P. Kent, R. Vega, A. Matukumalli, S. McWilliam, G. Sclep, K. Bryc, J. Choi, H. Gao, J. J. Grefenstette, B. Murdoch, A. Stella, R. Villa-Angulo, M. Wright, J. Aerts, O. Jann, R. Negrini, M. E. Goddard, B. J. Hayes, D. G. Bradley, M. Barbosa da Silva, L. P. L. Lau, G. E. Liu, D. J. Lynn, F. Panzitta, and K. G. Dodds. 2009. Genomewide survey of SNP variation uncovers the genetic structure of cattle breeds. Science 324:528-532.

Habier, D., R. L. Fernando, and J. C. M. Dekkers. 2007. The impact of genetic relationship information on genome-assisted breeding values. Genetics 177:2389-2397.

Habier, D., J. Tetens, F.-R. Seefried, P. Lichtner, and G. Thaller 2010. The impact of genetic relationship information on genomic breeding values in German Holstein cattle. Genet. Sel. Evol. 42:5.

Harris, B. L., and D. L. Johnson. 2010. Genomic predictions for New Zealand dairy bulls and integration with national genetic evaluation. J. Dairy Sci. 93:1243-1252.

Hayes, B. J., P. J. Bowman, A. C. Chamberlain, K. Verbyla, and M. E. Goddard. 2009. Accuracy of genomic breeding values in multibreed dairy cattle populations. Genet. Sel. Evol. 41:51.

Hill, W. G., and A. Robertson. 1968. Linkage disequilibrium in finite populations. Theor. Appl. Genet. 38:226-231.

International Committee for Animal Recording. 2012. International agreement of recording practices. Accessed Nov. 6, 2013. http:/ / www. 
icar.org/Documents/Rules\%20and\%20regulations/Guidelines/ Guidelines_2012.pdf.

Jorjani, H., J. Jakobsen, E. Hjerpe, V. Palucci, and J. Dürr. 2012. Status of genomic evaluation in the Brown Swiss populations. Interbull Bull. 46:46-54.

Karoui, S., M. J. Carabaño, C. Díaz, and A. Legarra. 2012. Joint genomic evaluation of French dairy cattle breeds using multiple-trait models. Genet. Sel. Evol. 44:39.

Kijas, J. W., D. Townley, B. P. Dalrymple, M. P. Heaton, J. F. Maddox, A. McGrath, P. Wilson, R. G. Ingersoll, R. McCulloch, S. McWilliam, D. Tang, J. McEwan, N. Cockett, V. H. Oddy, F. W. Nicholas, and H. Raadsma., and International Sheep Genomics Consortium. 2009. A genome wide survey of SNP variation reveals the genetic structure of sheep breeds. PLoS ONE 4:e4668.

Legarra, A., I. Aguilar, and I. Misztal. 2009. A relationship matrix including full pedigree and genomic information. J. Dairy Sci. 92:4656-4663.

Legarra, A., J. K. Bertrand, T. Strabel, R. L. Sapp, J. P. Sánchez, and I. Misztal. 2007. Multi-breed genetic evaluation in a Gelbvieh population. J. Anim. Breed. Genet. 124:286-295.

Legarra, A., C. Robert-Granié, E. Manfredi, and J. M. Elsen. 2008. Performance of genomic selection in mice. Genetics 180:611-618.

Lund, M. S., A. P. W. de Roos, A. G. de Vries, T. Druet, V. Ducrocq, S. Fritz, F. Guillaume, B. Guldbrandtsen, Z. Liu, R. Reents, C. Schrooten, F. Seefried, and G. Su. 2011. A common reference population from four European Holstein populations increases reliability of genomic predictions. Genet. Sel. Evol. 43:43.

Makgahlela, M. L., E. A. Mäntysaari, I. Strandén, M. Koivula, U. S. Nielsen, M. J. Sillanpää, and J. Juga. 2013. Across breed multitrait random regression genomic predictions in the Nordic Red dairy cattle. J. Anim. Breed. Genet. 130:10-19.

Mäntysaari, E., Z. Liu, and P. VanRaden. 2010. Interbull validation test for genomic evaluations. Interbull Bull. 41:17-21.

McVean, G. 2009. A genealogical interpretation of principal components analysis. PLoS Genet. 5:e1000686.

Misztal, I., Z. G. Vitezica, A. Legarra, I. Aguilar, and A. A. Swan. 2013. Unknown-parent groups in single-step genomic evaluation. J. Anim. Breed. Genet. 130:252-258.

Olson, K. M., P. M. VanRaden, and M. E. Tooker. 2012. Multibreed genomic evaluations using purebred Holsteins, Jerseys, and Brown Swiss. J. Dairy Sci. 95:5378-5383.

Olson, K. M., P. M. VanRaden, M. E. Tooker, and T. A. Cooper. 2011. Differences among methods to validate genomic evaluations for dairy cattle. J. Dairy Sci. 94:2613-2620.

Pszczola, M., H. A. Mulder, and M. P. L. Calus. 2011. Effect of enlarging the reference population with (un)genotyped animals on the accuracy of genomic selection in dairy cattle. J. Dairy Sci. 94:431-441.
Quaas, R. L. 1988. Additive genetic model with groups and relationships. J. Dairy Sci. 71:1338-1345.

Su, G., P. Madsen, U. S. Nielsen, E. A. Mäntysaari, G. P. Aamand, O. F. Christensen, and M. S. Lund. 2012. Genomic prediction for Nordic Red Cattle using one-step and selection index blending. J. Dairy Sci. 95:909-917.

Sved, J. A. 1971. Linkage disequilibrium and homozygosity of chromosome segments in finite populations. Theor. Popul. Biol. 2:125141.

Tenesa, A., P. Navarro, B. J. Hayes, D. L. Duffy, G. M. Clarke, M. E. Goddard, and P. M. Visscher. 2007. Recent human effective population size estimated from linkage disequilibrium. Genome Res. 17:520-526.

Thomasen, J. R., C. Egger-Danner, A. Willam, B. Guldbrandtsen, M. S. Lund, and A. C. Sørensen. 2014. Genomic selection strategies in a small dairy cattle population evaluated for genetic gain and profit. J. Dairy Sci. 97:458-470.

Tsuruta, S.. I. Misztal, and I. Strandén. 2001. Use of the preconditioned conjugate gradient algorithm as a generic solver for mixedmodel equations in animal breeding applications. J. Anim. Sci 79:1166-1172.

Ugarte, E. 2007. The breeding program of Latxa breed. Biotechnol. Anim. Husbandry 23:97-111.

Ugarte, E., E. Urarte, F. Arrese, J. Arranz, L. Silio, and C. Rodriguez. 1996. Genetic parameters and trends for milk production of blond-faced Latxa sheep using Bayesian analysis. J. Dairy Sci 79:2268-2277.

Vandenplas, J., and N. Gengler. 2012. Comparison and improvements of different Bayesian procedures to integrate external information into genetic evaluations. J. Dairy Sci. 95:1513-1526.

VanRaden, P. M., and G. R. Wiggans. 1991. Derivation, calculation, and use of national animal model information. J. Dairy Sci. 74:2737-2746.

VanRaden, P. M. 2008. Efficient methods to compute genomic predictions. J. Dairy Sci. 91:4414-4423.

VanRaden, P. M., K. M. Olson, G. R. Wiggans, J. B. Cole, and M. E. Tooker. 2011. Genomic inbreeding and relationships among Holsteins, Jerseys, and Brown Swiss. J. Dairy Sci. 94:5673-5682.

VanRaden, P. M., C. P. V. Tassell, G. R. Wiggans, T. S. Sonstegard, R. D. Schnabel, J. F. Taylor, and F. S. Schenkel. 2009. Invited review: Reliability of genomic predictions for North American Holstein bulls. J. Dairy Sci. 92:16-24.

Vitezica, Z. G., I. Aguilar, I. Misztal, and A. Legarra. 2011. Bias in genomic predictions for populations under selection. Genet. Res. (Camb.) 93:357. 